Available online at GSC Online Press Directory

GSC Biological and Pharmaceutical Sciences

e-ISSN: 2581-3250, CODEN (USA): GBPSC2

Journal homepage: https://www.gsconlinepress.com/journals/gscbps

(RESEARCH ARTICLE)

\title{
Outbreak of infectious bursal disease in a flock of 14 weeks old ISA brown pullets,
} Sokoto State, Nigeria

\author{
Mohammed Usman Mera ${ }^{1,}$ Garba Sirajo ${ }^{1}$ and Armiya'u Rukayya ${ }^{2}$ \\ ${ }^{1}$ Department of Veterinary Medicine, Usmanu Danfodiyo University, Sokoto, Nigeria. \\ ${ }^{2}$ State College for Basic and Remedial Studies, Sokoto State, Nigeria.
}

Publication history: Received on 22 September 2019; revised on 07 October 2019; accepted on 24 October 2019

Article DOI: https://doi.org/10.30574/gscbps.2019.9.2.0182

\begin{abstract}
This study reported the clinical signs and pathological effects of Infectious bursal disease (IBD) virus in 14 week old Isa brown IBD- vaccinated pullets. Clinical signs, pathologic lesions, morbidity as well as mortality rates on the natural outbreak of infectious bursal disease (IBD) in pullets under deep litter system in a commercial poultry farm in Sokoto, Nigeria were observed and recorded. Tissues of bursa of Fabricius (BF) were collected and fixed in 10\% buffered formalin and processed for histopathological examinations. During the outbreak, morbidity and mortality rate of $40 \%$ and $22 \%$ respectively were recorded and the disease course lasted for 7 days. The disease was diagnosed based on clinical signs, gross- and histo- pathologic lesions as well as agar gel immunodiffusion test (AGID). Clinical signs, gross lesions, and histopathological findings were characteristic of very virulent infectious bursal disease.
\end{abstract}

Keywords: Infectious bursal disease; Pullets; Clinical Signs; Pathologic lesions; Bursa of Fabricius

\section{Introduction}

Poultry production has witnessed a rapid growth in the last decades as a commercial enterprise involving hundreds of thousands of birds and has given rise to new challenges especially those of disease control (Hassan et al., 2007). One of the major constraints of poultry production in Nigeria are infectious diseases, among which viral diseases are the most important due to high morbidity and/or mortality often associated with these diseases (Adene, 2004).

Infectious bursal disease (IBD) also referred to as Gumboro disease has been considered as one of the important viral diseases of commercial chickens threatening the poultry industry worldwide (Müller et al., 2003). It has been reported that, low return on investment has been experienced due to IBD outbreaks in the poultry industries of both developing and developed nations (Sainsbury, 2000). The disease is caused by IBD virus and is an acute and highly contagious disease in chickens at 3 weeks of age and older. There are two distinct serotypes of IBD virus namely: serotype 1 and serotype 2. Both serotypes can infect chickens and turkeys but the clinical disease is recognized only in chickens (Yamaguchi et al., 1996). Only serotype 1 is virulent for chickens, replicating within the lymphoid cells of the bursa of Fabricius and destroying them, thereby inducing immunosuppression (Lukert and Saif, 2008). It causes high mortality and immunosuppression in recovered chickens leading to variety of secondary infections and decreased response to vaccinations, which results in an important economic impact to the poultry industry worldwide (Vandenberg et al., 2000). Infectious bursal disease virus (IBDV) targets the bursa of Fabricius (BF), causing damage by destroying developing B- lymphocytes. Several clinical forms are observed in the field ranging from mild immunosuppression to high mortality (90 to 100\%) (Vandenberg et al., 2000). Different modified live vaccines (MLVs) containing classical or variant viruses are commercially available and classified according to their degree of attenuation as mild, intermediate, intermediate plus and hot IBD vaccines (Vandenberg et al., 2000; Müller et al., 2003). Mild and intermediate vaccines

\footnotetext{
${ }^{*}$ Corresponding author

E-mail address: usmanmera2@gmail.com
} 
are safer in that they cause less bursal damage than hot vaccines, but have poor efficacy in the presence of maternally derived antibody (MDA) and against very virulent IBD viruses (vvIBDVs). In contrast, less attenuated strains (intermediate plus and hot vaccines) can overcome higher levels of MDA, but cause more severe lesions in the bursal follicles, resulting in immunosuppression (Prandini et al., 2008). Clinical outbreaks in vaccinated flocks are reported (Islam et al., 2008). Neutralization of the vaccine viruses by the MDA has been considered as one of the factors for causing vaccination failure. To overcome this problem, relatively virulent strains of vaccine viruses with higher residual pathogenicity for example intermediate strains and intermediate plus strains have been introduced (Kouwenhoven and Van den Bos, 1994). The better protection with more virulent strains of IBD virus is due to more antigenic stimulation based on higher and longer replication in lymphoid tissues (Rautenschlein et al., 2001). However, these intermediate vaccine strains may produce moderate to severe bursal lesions and immunosuppression in vaccinated chickens as reported by Franciosini and Coletti (2001) and Boudaoud and Alloui (2008).

We report an outbreak of gumboro disease in gumboro disease vaccinated flock, where typical sings and lesions of the disease were observed and further confirmed by serology and histopathology of the bursa of Fabricious.

\section{Material and methods}

\subsection{Study area and case history}

Outbreak of unknown disease was reported to the avian clinic of the Veterinary Teaching Hospital, Usmanu Danfodiyo University, Sokoto, from a commercial poultry farm in Tamaje area, Sokoto metropolis along eastern bye- pass, Sokoto state. The chickens were 14 weeks old Isa brown breed and the farm manager observed a sudden high mortality. The birds were raised in deep litter system and fed on growers mash. They were vaccinated against ND at 3 weeks with NDLa Sota vaccine and 7 weeks with ND- Komarov vaccine as well as against gumboro disease at 1 and 4 weeks old with IBD vaccines at $10 \mathrm{~mL}$ reconstitution per bird via drinking water respectively.

\subsection{Sample collection and processing}

Tissues were collected for virological, bacteriological, and histopathological examination. Bursae of Fabricius (BFs) were aseptically harvested into universal bottles and stored at $-20^{\circ} \mathrm{C}$ for viral detection. Liver was sent for bacterial culture and identification. Tissues including spleen and BF were fixed in $10 \%$ neutral buffered formalin for histological examination. The fixed tissues were processed routinely for histopathology stained with haematoxylin and eosin and examined with the light microscope.

Frozen samples of the BFs were homogenised into $50 \% \mathrm{w} / \mathrm{v}$ suspension in phosphate buffered saline (PBS). The homogenate was centrifuged at $2000 \mathrm{rpm}$ for 30 minutes and the supernatant was harvested and tested for IBD virus using AGID test as described by OIE (2008).

\section{Results}

\subsection{Clinical evaluation}

The clinical signs observed were ruffled feather, somnolence, depression, huddling and milky-watery faeces. The morbidity and mortality rate were $40 \%$ and $22 \%$ respectively. The mortality patterns are shown in Figure 1.

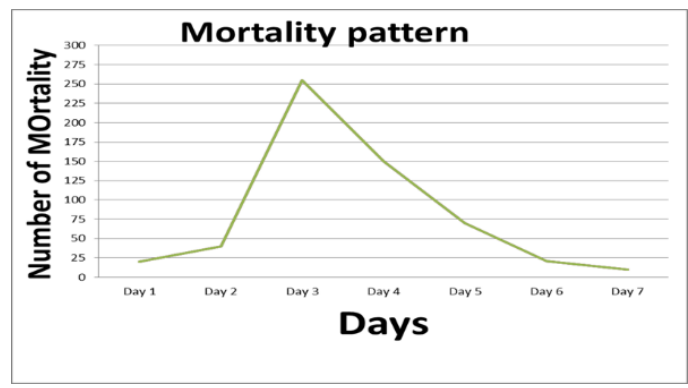

Figure 1 Mortality Pattern 


\subsection{Postmortem findings}

The carcasses were moderately dehydrated. There were petechial and ecchymotic haemorrhages on the pectoral, thigh and leg muscles and caecal tonsils and at the junction between proventriculus and ventriculus. The liver was congested and the spleen was enlarged and mottled. In most cases the bursa of Fabricius was edematous and haemorrhagic with yellowish gelatinous exudate on the mucosal surface. The kidneys were swollen and congested as well as catarrhal enteritis.

Hemorrhages of legs, thigh and keel Muscle $5 / 9$

Congested lungs $9 / 9$

Hemorrhagic Bursa of fabricius $9 / 9$

Enlarged Bursa of fabricius $8 / 9$

Atrophied Bursa of fabricius $1 / 9$

Congested liver $5 / 9$

Catarrhal enteritis $9 / 9$

Congested kidneys $9 / 9$

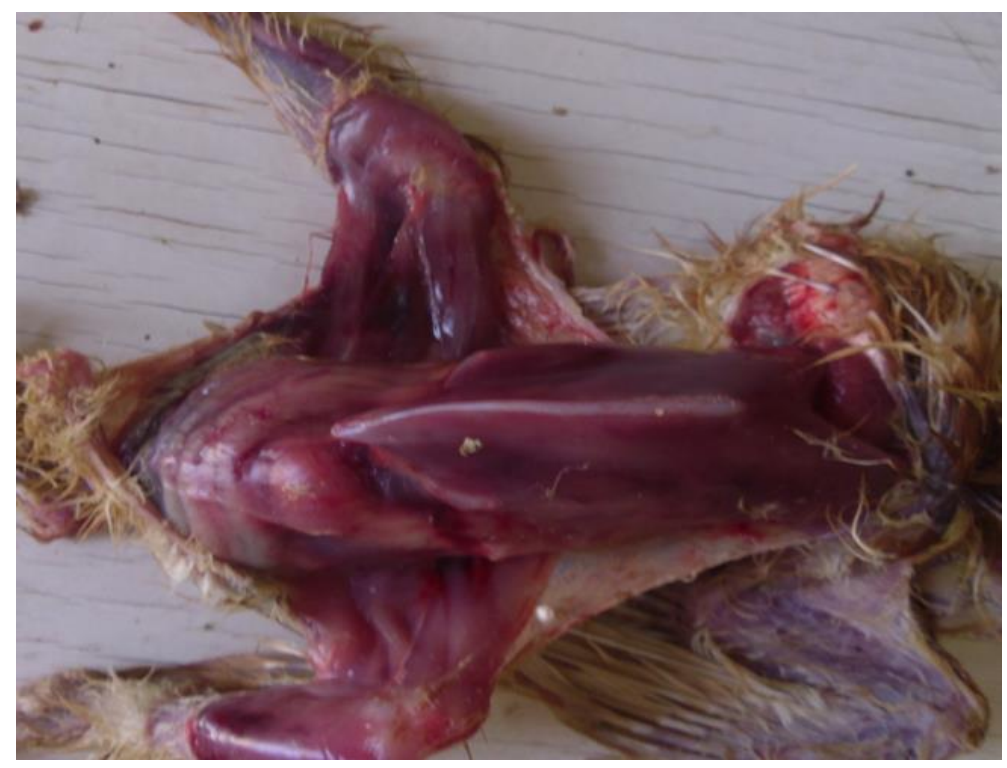

Figure 2 Showing hemorrhages on legs (arrow), thigh (arrow head) and keel (double arrows) Muscle

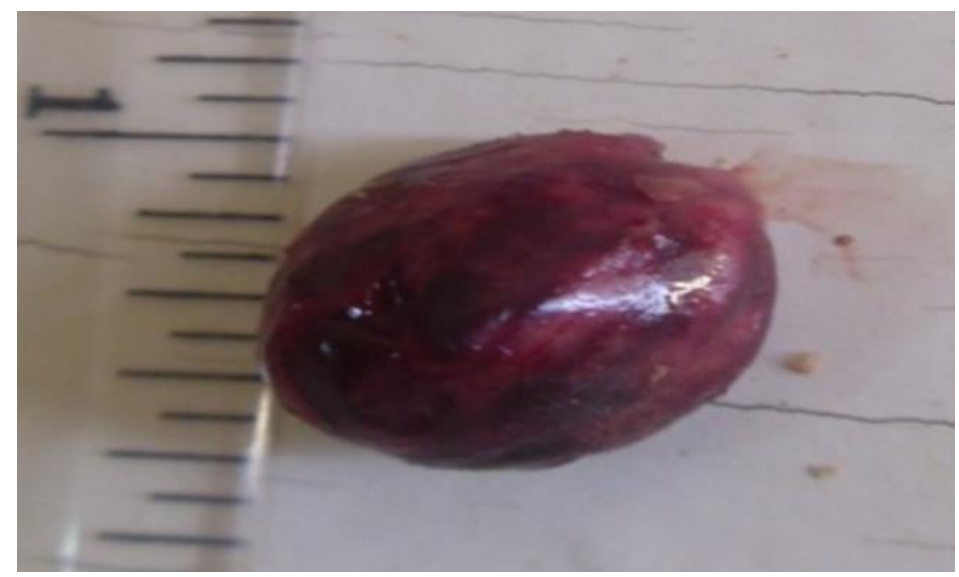

Figure 3 Enlarged, oedematous and haemorrhagic bursa of Fabricius 
Mohammed et al. / GSC Biological and Pharmaceutical Sciences 2019, 09(02), 001-008

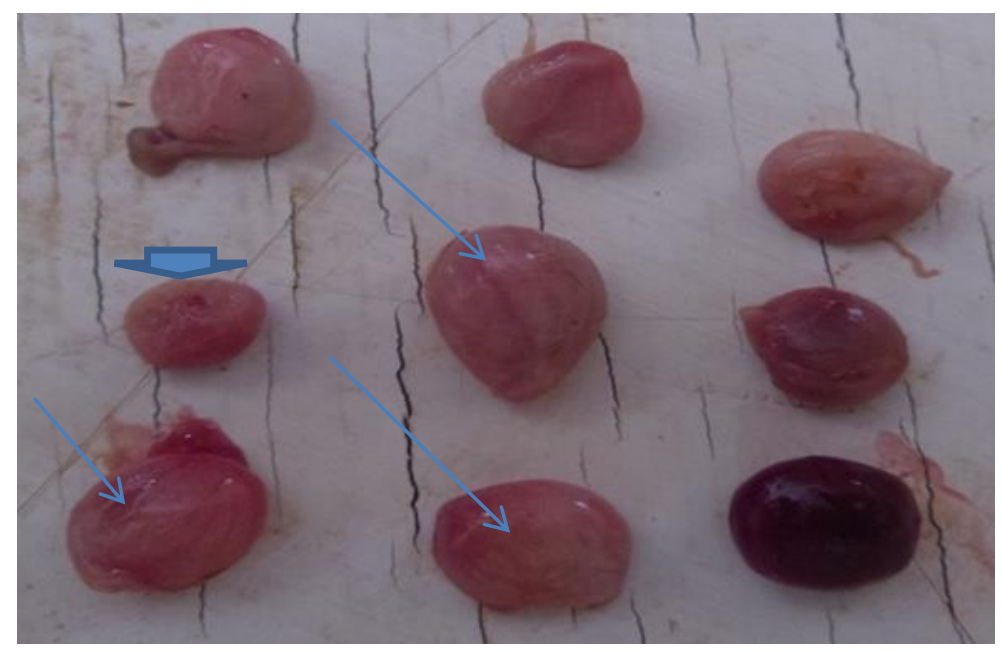

Figure 4 Different degree of enlarged (arrows) hemorrhagic and atrophic (arrow head) bursa of Fabricius

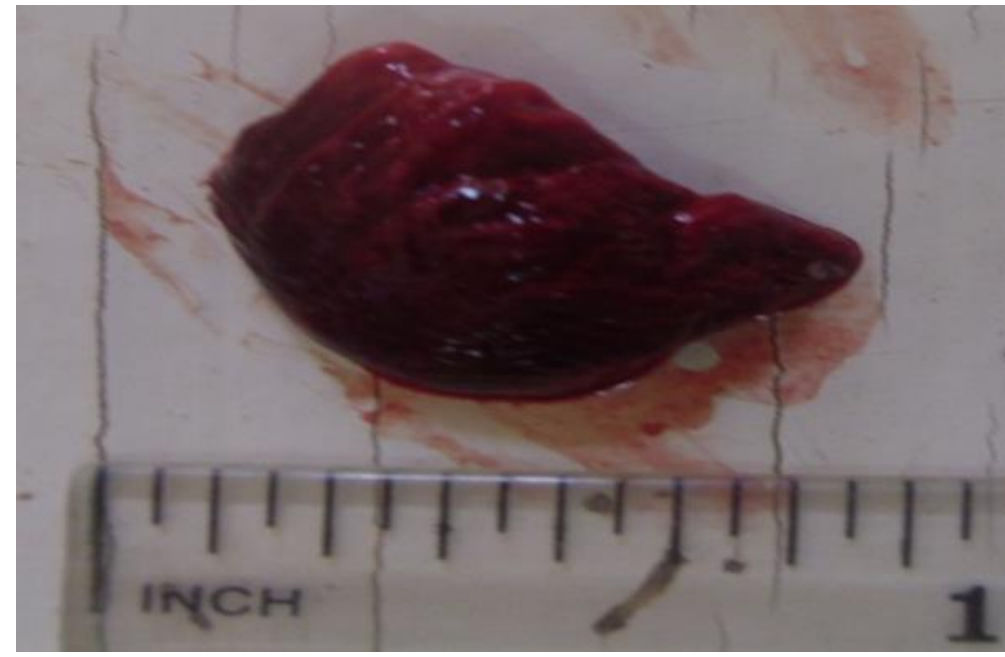

Figure 5 Congested lung

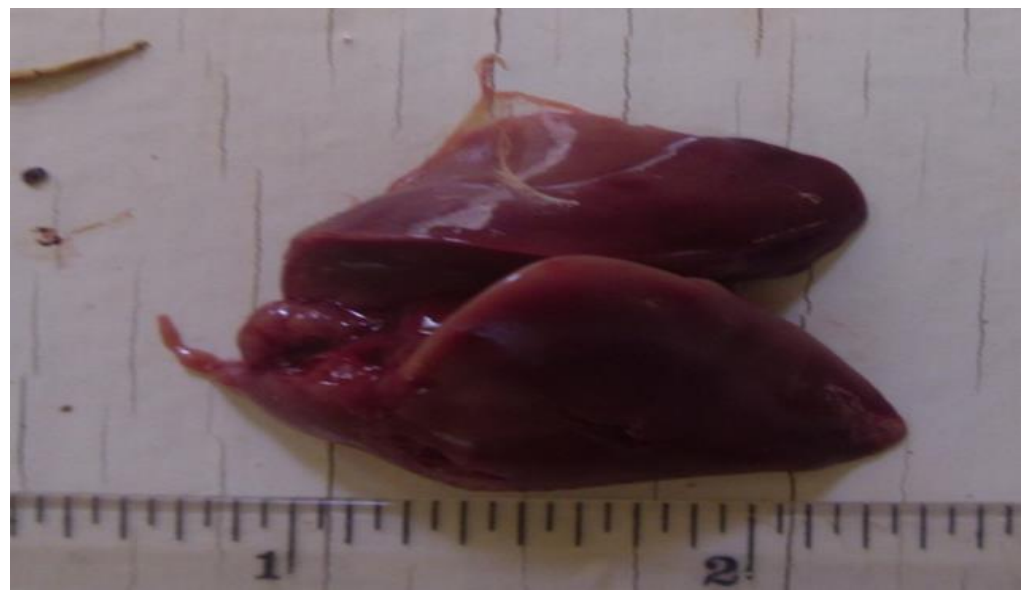

Figure 6 Congested liver 


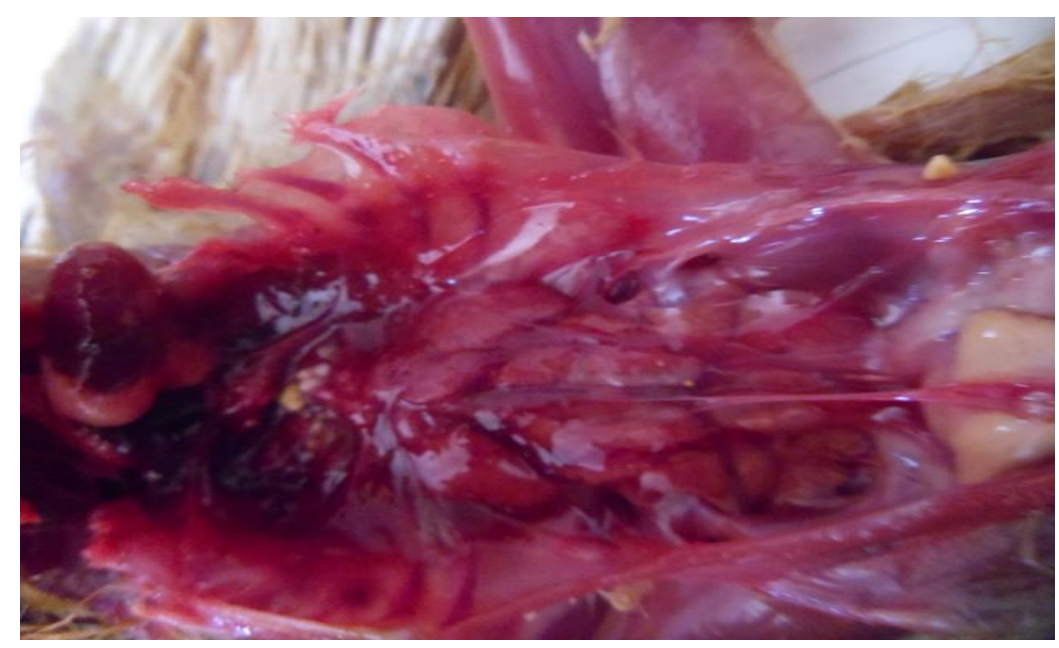

Figure 7 Enlarged and congested kidney (arrows)

\subsection{Histopathological findings}

There was marked interfollicular oedema and depletion of lymphocytes from the lymphoid nodules in the BFs. Other lymphoid nodules of the BF showed degeneration and necrosis of lymphocytes and cystic cavitations. The spleen showed moderate lymphoid depletion in the lymphoid nodules.

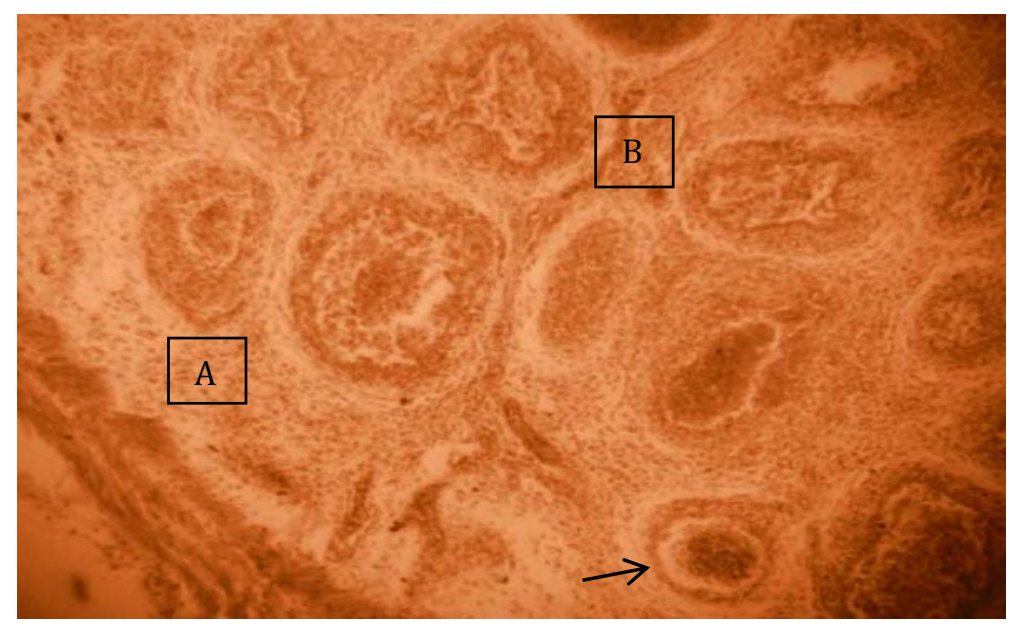

Figure 8 Showing severe follicular lymphoid depletion (A), interfollicular oedema (B) and follicular cyst (arrows) in the BF. $\mathrm{H}$ and $\mathrm{E} \times 200$

\subsection{Bacteriological and virological examinations}

Escherichia coli were isolated from the liver and cloacal sample after $24 \mathrm{hrs}$ of incubation at $37{ }^{\circ} \mathrm{C}$. Sensitive to: Gentamycin, Oxfloxazole, Nitrofurantoin. Resistance: Cotrimoxazole, Ofloxacin, Nalidixic acid. The bursal homogenate gave positive reactions to the IBDV known antiserum.

\subsection{Treatment/ management}

The birds were treated with Neoceryl powder at 1g/L of water, V-ox granules (mixture of inorganic peroxygen compounds; Polchem Hygiene Laboratories Pvt. Limited, India) at $1 \mathrm{~g} / \mathrm{L}$ of water, Vitavet $囚$ (multivitamins, vitamins A, B, E, D, and K, Pharma-Swede, Egypt) at $1 \mathrm{~g} / 2 \mathrm{~L}$ of water and glucose at $1 \mathrm{~g} / \mathrm{L}$ of water for 3 days.

\section{Discussion}

Gumboro disease is characterized by short incubation period of 2-3 days, and course of 5-6 days. Hemorrhages in skeletal muscles, proventriculus and enlargement of the bursa of Fabricius are some of the common lesions seen at post mortem (Lukert and Hitchner, 1997). In this report, the post mortem findings and death pattern observed were 
consistent with Gumboro disease. The diagnosis was confirmed by histopathology and IBD antigen detection in the bursa of Fabricius. This indicates an outbreak of IBD in a double vaccinated 14 weeks old flock. However, the age (14 weeks old) at which these birds had the outbreak was not inconformity with the common reported cases of IBD (mostly between 3 to 7 weeks old). But similar findings in vaccinated mature flocks aged between 16 and 20 weeks have been previously reported in Nigeria (Okoye and Ozoukwu, 1981; Durojaye et al., 1984, Awolaja and Adene, 1995). The IBD outbreak therefore might be attributed to the vaccine failure or vaccine break. In highly susceptible and unvaccinated flock, morbidity associated with the disease is usually $100 \%$ with mortality reaching $100 \%$ by very virulent IBDV. Thus, the lower morbidity and mortality rates recorded in this report suggested that the flock was susceptible to Gumboro disease but they had a level of acquired immunity possibly from the previous vaccines administered. Also, the immature $B$ cells are always the target cells to be attacked by the IBD virus and at that age (14 weeks old) most of the B cells might have been matured. This agrees with earlier finding that severity of IBD was related to the number of susceptible B cells present in the bursa of fabricius at the time of infection which is commonly seen between 4 and 6 weeks when the bursa of fabricius is at its maximum rate of development and the follicles are filled with immature B lymphocytes (Lukert and Saif, 1997; Rautenschelin et al., 2003). Most outbreaks of IBD in chickens under 3 weeks of age have been reported to be subclinical with bursal lesions and immunosuppression (Okoye and Shoyinka, 1983). However, the subclinical infections are economically important due to severe and long lasting immunosuppression; such birds do not respond to vaccinations and become susceptible to other diseases (Lukert and Saif, 1997; Baxendale, 1981).

The administration of neoceryl was to control the secondary bacterial infections. Vaccination at 7th day post hatch without screening for maternal antibody may be one of the sources of the problem because maternal derived antibody might have possibly neutralized the vaccine virus. Furthermore, at the 14th week, the IBD vaccinal immunity might have waned drastically and such a flock would be susceptible to IBD virus infection in the pen or to cross infection from adjacent sources. Loss of vaccine potency due to cold chain storage failure could be one of the possible factors that attributed to the flock's susceptibility to IBD outbreak. Mainatining cold chain is often difficult to attain in most developing countries of tropical Africa including Nigeria because of erratic power supply (Masiga et al., 1988). Other possible factors could be associated with emergence of pathotype variants which could overcome the current IBD vaccine immunity. Moreover, this outbreak occur during the first week of January, 2017 and Sokoto state is known of having very harsh dry wind during that period. Thus, that might serve as a stress on the birds thereby indirectly affecting their general performance and immunocompetence.

The use of IBD vaccines against current IBD virus in circulation in an area, effective biosecurity measures, proper decontamination and appropriate use of disinfectants and observing an adequate fallow period before restocking following outbreaks will assist in controlling further outbreaks. Meanwhile, passive protection via breeder vaccination and adequate progeny vaccination will protect birds against the menace of IBDV to a greater extent (Baxendale, 1981).

Birds that recover from natural infections remain strongly immuned while chicks with high maternal antibody if vaccinated with live vaccines may be rendered poorly immunocompetent (Baxendale, 1981). Additionally, a high degree of immune variation is been reported to exist between naturally occurring IBD and vaccine available (Baxendale, 1981). This leaves the Veterinarian and his client in a greater confusion in an attempt to effectively prevent IBD especially where laboratory facilities are inadequate. In this respect therefore, there is the need to produce bio-engineered vaccines based on the types of pathogenic IB viruses present in Nigeria.

\section{Conclusion}

In conclusion, the IBD vaccines currently being used to vaccinate birds against IBD in Nigeria may be antigenically different from the IBD virus circulating in our environment. There is therefore the need for effective biosecurity measures with sufficient fallow period before restocking of birds after an IBD outbreak in a poultry farm. The findings of this study have shown that V-ox and Neoceryl antibiotic given orally in chickens will not prevent typical IBD lesions in case of field exposure.

Studies should be directed towards elucidating the monitoring of IBD pathotypes in our environment. Birds should be routinely sero-monitored in order to know the level of protective anti bodies against IBD and for the planning of IBD vaccination regimen. Poultry farmers should be advised on the need for good management practices.

We also recommend a continuous search for an appropriate timing of IBD vaccination in chickens to keep pace with the ever increasing demand for poultry products in Nigeria. 


\section{Compliance with ethical standards}

\section{Acknowledgments}

We sincerely acknowledged the management of the Veterinary Teaching Hospital, Usmanu Danfodiyo University, Sokoto for allowing us to use their diagnostic facilities.

\section{Disclosure of conflict of interest}

The authors do not have any potential conflict of interest to declare.

\section{References}

[1] Adene DF. (2004). Synoptic notes on vaccines and their application in major diseases of poultry. In: Poultry Health and Production. Stirling Horlden, Ibadan, Nigeria, 181-187.

[2] Awolaja OA and Adene DF. (1995). Infectious bursal disease outbreak in a vaccinated poultry flock. Tropical Veterinarian 13, 1-2, 37-44.

[3] Baxendale W. (1981). Immunity to Infectious Bursal Disease. In: Avian Immunology, Rose, M.E., L.V. Payne and B.M. Freeman (Eds.). Edinburg British Poultry Science Ltd., Harlow, Essex, UK., 225-227.

[4] Boudaoud A and Alloui N. (2008). Evaluation of the safety of live attenuated vaccine viruses against infectious bursal disease (Gumboro disease) in conventional broiler chicks. Revue scientifique et technique (International Office of Epizootics), 27(3), 793-802.

[5] Durojaye OA, Ajibade HA and Olafimihan GO. (1984). An outbreak of Infectious bursal disease in 20-week old birds. Tropical Veterinarian, 2, 175-176.

[6] Franciosini MP and Coletti M. (2001). Serological, Histological and Immune- Histochemistry Studies on Infectious Bursal Disease Vaccine Strains with Residual Pathogenicity. In Immunosuppressive viral diseases in poultry, Proceedings 1999, European Commission Cost Action, 839, 199- 206.

[7] Hassan AA, Nwanta J and Mohammed A. (2007). Profitability Analysis of Poultry Egg Production in Kaduna State. Nigerian Veterinary Journal, 27, 8- 16.

[8] Islam MN, Rashid SMH, Hoque MF, Juli MSB and Khatun M. (2008). Pathogenicity of Infectious Bursal Disease virus related to outbreaks in vaccinated flocks and the causes of vaccination failure. Journal of Innovation and Develpment Strategy, 2, 22- 30.

[9] Kouwenhoven, B and Vanden Bos J. (1994).Control of Very Virulent Infectious Bursal Disease in the Neitherlands with more Virulent Vaccines. In International Symposium on Infectious Bursal Disease and Chick Infectious Anaemia. Rauischholzhausen, Germany, 262- 271.

[10] Lukert PD and Hitchner SB. (1997). Infectious bursal disease. In: Diseases of poultry 10th editon. Edited by Calnek, B. W., Barnes, H. J., Beard, C. W., McDougald, L. B. and Saif, Y. M. Iowa State University Press, Ames, 721738.

[11] Lukert PD and Saif YM. (2008). Infectious Bursal Disease. In Y. M. Saif et al., eds. Diseases of Poultry. Iowa: Iowa State Press, Ames, 161- 179.

[12] Lukert PD and YM Saif. (1997). Infectious Bursal Disease. In: Diseases of Poultry, 10th Edn., Calnek, B.W., H.J. Barnes, C.W. Beard, L.R. McDougald and Y.M. Saif (Eds.). Iowa State University Press, Ames., 721-738.

[13] Masiga WN, Halpin B and Cheneau Y. (1988). A review of riderpest and riderpest-like diseases in Africa. A. 0. Williams and W. N. Masiga ed. CTA of ACP/EEC (Lome Convention). 1-68.

[14] Müller H, Islam R and Raue R. (2003). Research on infectious bursal disease- the past, the present and the future. Veterinary Microbiology, 97, 153-165.

[15] Office International des Epizooties. (OIE). (2008). "Infectious bursal disease," in Terrestrial Manual, 555-557.

[16] Prandini F, Bublot M, Le Gros FX, Dancer A, Pizzont L and Lamichlane C. (2008). Assessment of the immune response in broilers and pullets using two ELISA kits after in ovo or day-old vaccination with a vectored HVT + IBD vaccine (VAXXITEK@ HVT+IBD). World Poultry Journal, 19, 21. 
[17] Rautenschelin S, HY Yeh and JM Sharma. (2003). Comparative immunopathogenesis of mild, intermediate and virulent strains of classic infectious bursal disease virus. Avian Dis., 47, 66-78.

[18] Rautenschlein S, Yehand HY and Sharma JM. (2001). A comparison of the immunopathogenesis of different Infectious Bursal Disease virus strains. In Proceedings of the 11th International Symposium on Infectious Bursal Disease and Chick Infectious Anaemia. Rauischholzhausen, Germany: Rauischholzhausen, 3, 311- 323.

[19] Sainsbury D. (2000).Infectious Bursal Disease. In Poultry Health and Management.Blackwell Publishers, Oxford, UK, 125- 126.

[20] Vandenberg TP, Eterradossi N, Toquin D and Meulemans G. (2000). Infectious bursal disease (Gumboro disease). Revue scientifique et technique (International Office of Epizootics), 19(2), 509-543.

[21] Yamaguchi T, Kondo T, Inoshima Y, Ogawa M, Miyoshi M, Yanai T, Masegi T, Fukushi H and Hirai K. (1996). In vitro attenuation of highly virulent infectious bursal disease virus: some characteristics of attenuated strains. Avian diseases, 40(3), 501-9.

\section{How to cite this article}

Mohammed UM., Garba S and Armiya'u R. (2019). Outbreak of infectious bursal disease in a flock of 14 weeks old ISA brown pullets, Sokoto State, Nigeria. GSC Biological and Pharmaceutical Sciences, 9(2), 01-08. 